\title{
Psychiatric Referral Pattern in a General Hospital
}

\author{
Vaidya Leepa $^{1}$, Sharma Rajan ${ }^{1}$
}

\author{
Corresponding Author: \\ Dr Leepa Vaidya \\ Consultant Psychiatrist \\ Department of Psychiatry, \\ Pokhara Academy of Health \\ Sciences, Western Regional \\ Hospital, Pokhara, Nepal
}

E-mail: leepavaidya@gmail.com

Article received : February 13, 2018

Article accepted : March 18, 2018

\begin{abstract}
Background: The referral rates of psychiatric patients in Nepal are very low, considering the higher rates of psychiatric morbidity in patients who attend various departments of a general hospital. Studying the pattern of psychiatric referrals may facilitate the management of the mentally ill in a comprehensive and holistic manner. Materials and methods: The study was conducted at Western Regional Hospital (WRH) over the period of one year. The patients referred from different departments were assessed by the consultant psychiatrists. Result: A total of 816 patients were referred for psychiatric consultation out of which majority was from department of medicine and the most common reason for referral was anxiety disorder. Conclusion: Multidisciplinary interaction is beneficial to identify the psychiatric morbidity in the patients who attend general hospital.
\end{abstract}

Keywords: Psychiatric referral, anxiety, mental health

\section{INTRODUCTION}

Treatment of the medically ill has been carried out in hospitals since ancient Greco-Roman times while the mentally ill have been cared for in asylums, sanctuaries etc. ${ }^{1}$ Pioneering physicians of the $19^{\text {th }}$ century believed in the psychosomatic unity of the human beings and many cases of mentally ill were treated in general hospitals. Consequently, the practice of referrals for psychiatric patients in general hospitals took a turn for the better. History of mental health services in Nepal is not long. Mental health services in Nepal remained unknown till 1961 AD. First psychiatric Out Patient Department (OPD) services were started in 1961 at Bir Hospital, Kathmandu. A five-bedded in-patient department in the same hospital was started in 1965. In 1972, a ten bedded neuro psychiatric unit was established in the Royal Army Hospital, which was then shifted into the Lagankhel, Patan and it has got fifty beds at present. ${ }^{2}$

General hospital psychiatry has grown significantly over the years. It has led to the changes in our understanding to provide a comprehensive and holistic approach to the physically and mentally ill. The general hospital psychiatric units have to exercise the expertise in the diagnosis and treatment of psychiatric disorders and also manage complex medically ill patients. It usually involves three groups of patients. i) somatoform and functional disorders ii) co-morbid psychiatric and medical illnesses and iii) psychiatric disorders that are secondary to medical conditions or its treatment. ${ }^{3}$

\section{MATERIALS AND METHODS}

The present study was conducted at the Western Regional Hospital, Pokhara. The study population consisted of all the patients referred to psychiatry OPD from other departments (OPD + Inpatients) during a period of one year (13 ${ }^{\text {th }}$ April 2016 till $13^{\text {th }}$ April 2017). All the referred cases were evaluated by consultant psychiatrist and diagnosis was made according to the diagnostic guidelines, as per ICD-10 (International Classification of Diseases). ${ }^{4}$ The other details like socio-demographic profile, source of referral were also recorded. The data obtained was analysed by using descriptive statistical methods.

\section{RESULT}

Total 5491 number of patients was seen in one year period in psychiatry OPD of Western Regional Hospital. A total of 816 patients were referred from different departments during the study period. Both outpatient and inpatient referrals were included in the study.

Out of 816 patients, 508 were female and 308 were male. 
Fig. 1 shows that the majority of the patients were in the age range of 21-40 years, followed by 41-60 years age range.

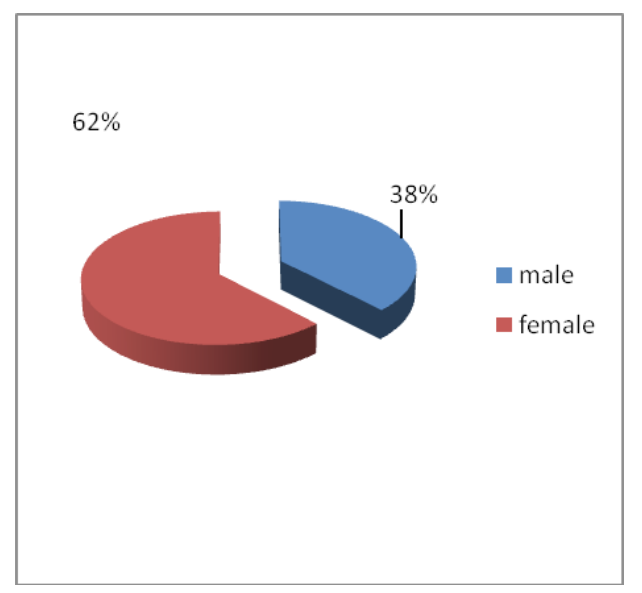

Fig. 1. No. of patients in percentage according to sex

The majority of the patients were referred from medicine department (n- 470, 57.59\%) both from medical OPD and medical ward. Among them, majority of the cases were referred from the OPD with multiple somatic problems due to anxiety and the ward patients were mainly alcohol dependent cases referred for their withdrawal symptoms. There were a significant number of cases with suicidal attempt who were sent to psychiatry department to evaluate the cause of attempt. The most common psychiatric diagnosis was anxiety disorder followed by depression and alcohol related disorders.

Table 1: Referring Departments

\begin{tabular}{lll}
\hline Department & Number & Percentage \\
\hline Medicine & 470 & $57.6 \%$ \\
Emergency & 109 & $13.3 \%$ \\
Surgery & 68 & $8.3 \%$ \\
Orthopedics & 67 & $8.2 \%$ \\
\hline Pediatrics & 34 & $4.16 \%$ \\
ENT & 18 & $2.2 \%$ \\
Dental & 18 & $2.2 \%$ \\
Gynecology/Obstetrics & 12 & $1.5 \%$ \\
\hline Dermatology & 10 & $1.2 \%$ \\
\hline ICU & 10 & $1.2 \%$ \\
\hline
\end{tabular}

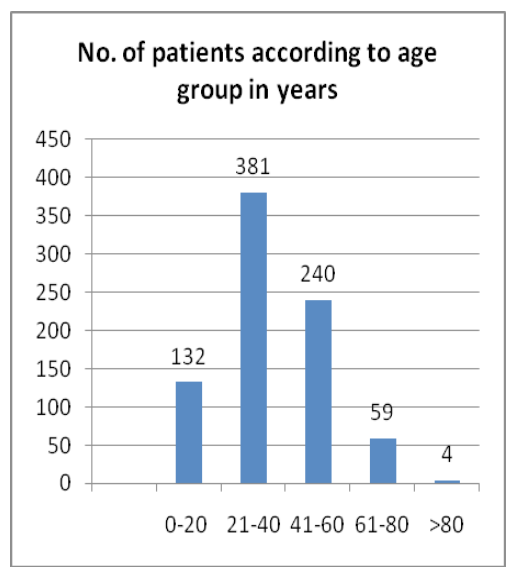

Fig.2. No. of patients according to age group

Table 2: Psychiatric Diagnosis

\begin{tabular}{lcc}
\hline Diagnosis & Frequency & Percentage \\
\hline Anxiety & 364 & $44.6 \%$ \\
Depression & 106 & $12.9 \%$ \\
Alcohol and substance & 74 & $9 \%$ \\
\hline Organic mental disorder & 65 & $7.9 \%$ \\
Somatoform disorders & 55 & $6.7 \%$ \\
\hline Deliberate self harm & 34 & $4.1 \%$ \\
Schizophrenia & 32 & $3.9 \%$ \\
No psychiatric disorders & 32 & $3.9 \%$ \\
Adjustment disorder & 22 & $2.6 \%$ \\
Dissociative disorder & 19 & $2.3 \%$ \\
Sleep disorders & 7 & $0.8 \%$ \\
Disorder of childhood & 5 & $0.6 \%$ \\
Obsessive Compulsive & & \\
Disorder & 1 & $0.1 \%$ \\
\hline
\end{tabular}

\section{DISCUSSION}

This study was a modest attempt to recognize the pattern of psychiatric referral in Western Regional Hospital, Pokhara. There was a predominance of female patients than the male patients ( $62 \%$ vs. $38 \%)$. Similar female predominance was seen in the study done by G. Suresh Kumar et $\mathrm{al}^{5}$. Age distribution showed that the majority of cases were in the age group 21-40 years $(n=381)$ followed by age group 41-60 years $(n=240)$. The findings were in agreement with the various studies. ${ }^{6-8}$ The youngest patient referred was 4 years old who had hydrocephalus and mental retardation and was referred for behavioral problem. The oldest patient was 90 years old man who was a known case of heart disease and was referred to psychiatry for altered sensorium due to delirium. Only 59 patients in the age range $61-80$ years and 4 patients in the age group $>80$ years which was in contrast 
to the findings in the study done by Huyse FJ. ${ }^{9}$ This may be due to various reasons like lack of awareness about geriatric conditions like dementia, family neglect and preference to alternative treatment measures like ayurveda, homeopathy, acupuncture etc.

On analyzing the source of referral, the majority of the cases, 470 patients $(57.59 \%)$ were referred from the department of medicine. Similar findings were seen in previous studies which have shown that $59 \%$ and $54.3 \%$ of cases were referred from department of medicine. ${ }^{10,11} \mathrm{~Pa}-$ tients with psychiatric disorders give much priority to the somatic symptoms due to which they tend to visit general physician rather than psychiatrists for the treatment of their physical symptoms. ${ }^{12,13,14,15}$ Another reason may be due to lack of awareness about the psychiatric origin of the physical symptoms and due to social stigma about the psychiatric illnesses.

When the psychiatric diagnosis of the referred patients was analyzed, neurotic disorders like anxiety disorder, depression, mixed anxiety depression, somatoform and stress disorders were the most common. This finding was in agreement with the majority of other previous studies. ${ }^{5-6,9-11,15}$ The reasons for their referral were mainly for multiple somatic complains which could not be explained

\section{REFERENCES}

1. Saldanha D, Bhattacharya L, Daw D, Chaudari B. Origin and development of general hospital psychiatry. Med J DY Patil Univ.2013Sep; 6(4):359-65.

2. Sharma VD. Mental Health in Nepal. South Asian Journal of Psychiatry.2011Mar;2(1):23-24

3. Levenson JL. The American Psychiatric Publishing Textbook of Psychosomatic Medicine. Psychiatric care of the medically ill. $2^{\text {nd }}$ Ed, Chapter 5-17 Washington DC: American Psychiatric Publishing : 2011.p 45-493

4. WHO. The ICD-10 Classification of mental and behavioral disorders: Guidelines, Geneva. 1992.

5. Kumar GS, Reddy KVR, Anushanemani. Inpatient psychiatric referrals to general hospital psychiatry unit in a tertiary care hospital in Andhra Pradesh. Journal of Dental and Medical Sciences.2015Jan;14(1):26-29. Available from: DOI: 10.9790/085314142629

6. Keertish N, Sathyanarayana MT, Hemanth Kumar BG, Singh N, Udagave K. J Clin Diagn Res. 2013 Aug; 7(8): 1689-1691.

7. Aghanwa H. Consultation Liaison Psychiatry in Fiji. Pacific Health Diag. 2002;9(1):21-28

8. BhogaleGS, Katte RM,Heble SP, Sinha UK, Patil PA. Psychi- through any medical diagnoses. Alcohol and substance related disorders were quite common. This may be due to the fact that patients with alcohol problem tend to come to the hospital only when they have co-morbid alcoholic liver disease or when they develop withdrawal symptoms after they get admitted in the hospital for other illness. It was very interesting to find that $3.9 \%$ of referred patients had no psychiatric problem and few had to be referred to other departments for further evaluation. Similar finding was found in a study where $7.3 \%$ of the referred patients had no psychiatric diagnosis. ${ }^{5}$

The above mentioned psychiatric disorders are not only common, but also lead to significant functional impairment. The introduction of psychotropic medicines has improved the quality of life of the psychiatric patients and prognosis is improved with proper use of medication which was previously considered untreatable.

\section{CONCLUSION}

Multidisciplinary interaction is beneficial to identify the psychiatric morbidity in the patients who attend general hospital, in order to facilitate early recognition and management of psychiatric problem.

atric referrals in multispeciality hospitals. Indian J Psychiatry. 2000;42:188-94

9. Huyse FJ, Herzog T, Lobo A, Malt UF, Opmeer BC, Stein B et al. Consultation-Liaison psychiatric service delivery results from a European study. General Hospital Psychiatry.2001;23:124-32

10. Jindal RC, Hemrajani DK. A study of psychiatric referrals in a general hospital. Indian J Psychiatry. 1980 Jan-Mar; 22(1): 108-10.

11. Dhavale HS, Barve RG. Psychiatric referral pattern in general hospital. J Postgrad Med. 1990;36:199-202

12. Doongaji DR, Nadkarni RP, Bhatawdekar ML. Psychiatric referrals in two general hospitals. J Postgrad Med. 1989;35:171-7

13. Grover S, Sahoo S, Aggarwal S, Dhiman S, Chakrabarti S, Avasthi A. Reasons for referral and diagnostic concordance between physicians/surgeons and the consultation-liaison psychiatry team: An exploratory study from a tertiary care hospital in India. Indian J Psychiatry. 2017 Apr-Jun; 59(2): 170-175. Available from: doi: 10.4103/psychiatry.IndianJPsychiatry_305_16

14. Al-Ansari EA, El-Hilu S, El-Hihi MA, Hasan KI. Patterns of psychiatric consultations in Kuwait general hospitals. Gen Hosp Psychiatry. $1990 \mathrm{Jul} ; 12(4): 257-63$

15. De Giorgio G, Quartesan R, Sciarma T, Giulietti M, Piazzoli A, Scarponi L et al. Consultation-Liaison psychiatry-from theory to clinical practice: an observational study in a general hospital. BMC Res Notes. 2015 Sep24; 8: 475. 